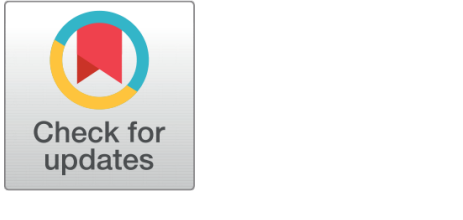

OPEN ACCESS

Received: 10-09-2020

Accepted: 13-09-2020

Published: 21.10 .2020

Editor: Dr. Natarajan Gajendran

Citation: Figueroa M, Mora O, Borrero D (2020) Relationship of operating speed with pavement serviceability from the pavement condition index. Case of study: Barranquilla, Colombia. Indian Journal of Science and Technology 13(37): 3904-3909. https://doi.org/ 10.17485/IJST/v13i37.764

* Corresponding author.

Tel: +57-318-891-6160

mfiguero12@cuc.edu.co

Funding: None

Competing Interests: None

Copyright: () 2020 Figueroa et al. This is an open access article distributed under the terms of the Creative Commons Attribution License, which permits unrestricted use, distribution, and reproduction in any medium, provided the original author and source are credited.

Published By Indian Society for Education and Environment (iSee)

ISSN

Print: 0974-6846

Electronic: 0974-5645

\section{Relationship of operating speed with pavement serviceability from the pavement condition index. Case of study: Barranquilla, Colombia}

\author{
Miguel Figueroa $^{1 *}{ }^{*}$, Otto Mora ${ }^{1}$, Diego Borrero ${ }^{1}$ \\ 1 Department of Civil and Environmental Engineering, Universidad de la Costa, Colombia. \\ Tel.: +57-318-891-6160
}

\section{Abstract}

Objectives: The present research aims to find the relationship in the field that the road condition index has concerning its operating speed, based on the expected assumption that the worse the condition index, the lower the road operating speed will be. Methodology: The methodology used to carry out this research consisted in the estimation of the condition index $(\mathrm{PCl})$ and the measurement of speeds in different road sections of the city of Barranquilla (Colombia), where a record of the surface conditions of the pavement from 0 when it was failed and 100 for pavement in excellent condition. In the case of speed recording, the plate method was used to obtain operating speeds. Then, using the UNALPCIA software, the value of the $\mathrm{PCl}$ of the evaluated road sections was estimated and then correlated with the operating speeds obtained in the field of those sections. Findings: The main findings obtained from the investigation consist of the effective relationship between the value of the $\mathrm{PCl}$ and the operating speed, having that the lower the condition index, the lower the operating speed on the road due to the presence of damage to the road pavement surface. Novelty: The study of the surface conditions of the pavement in the cities of Colombia is little studied, which leads to policies associated with the maintenance of pavement structures becoming late, given that the comfort and speed of operation allowed by these do not is appropriate, even though its structural function is still in force.

Keywords: Condition index; comfort; policies; surface condition

\section{Introduction}

For pavements to guarantee a level of comfort to users through their serviceability index, some criteria are proposed, which allow determining a rating according to the state of their structure. Through the development of serviceability models, it is sought that users make a judgment about the quality of the roads, taking as a reference various types of damage and the inconvenience they cause, but other methods of evaluation more in the field are also used, such as sampling, damage inventory and expert qualification, as 
established by the PCI (Pavement Condition Index) methodology. Currently, there are models designed to be widely applied in the field of roads, which are deterministic and base their accuracy on the criteria of road users, without taking into account the ability or knowledge of said users to make their judgments, which can generate deviations and errors in the results of the models ${ }^{(1)}$.

The emphasis of this research is to apply a model that adapts to the conditions of the pavement found in the city of Barranquilla, specifically in the northern town-historic center. When it comes to qualifying and determining the serviceability of pavements in the city, that it uses both deterministic and probabilistic models, which includes and takes into account factors that impact urban pavements and that can be applied in different places where the same characteristics exist as in Colombia ${ }^{(2)}$. The model applied for this study PCI (Pavement Condition Index) consists of the visual evaluation of this, taking as reference the 18 damages proposed by the method and based on the results obtained after the evaluation, a comparative analysis is carried out with the operating speeds given in the different sections evaluated ${ }^{(3)}$.

The quality of the road infrastructure is of great importance for the economic development of a country because this usually turns out to be the transport network with the greatest national coverage and the greatest accessibility, additionally, it is the one in which the greatest amount of transport is transported, merchandise, passenger transport, among others ${ }^{(4)}$. At the city level, road infrastructure plays a fundamental role in the quality of life of people, given the state of this affects the travel times of people and the transport of goods (operational costs) ${ }^{(3)}$.

A territorial entity must guarantee that the quality of the road infrastructure is in an optimal state and that resources are invested in its maintenance, since these can boost the economy and growth in a region, at the same time that they are synonymous with development and opportunities for the communities that have access to them.

According to the above, there is the importance of monitoring the road infrastructure, in terms of its useful life and its wear process over time (aging). Through this study, it is proposed to apply a serviceability model that qualifies the state of a pavement, using the PCI methodology (pavement condition index), which allows us to evaluate and qualify the state of rigid pavements. in the city. This is based on the results of a visual inventory of the condition of the pavement in which class, severity, and quantity of each present damage are established. On the other hand, it is also sought to make a comparative relationship between the visual method and the operating speeds; since the users of the system are those directly involved, as they are the ones who travel daily on these roads.

For this reason, it seeks to carry out studies of various roads in our city to evaluate and compare the pavement with this method, for which as a first measure, the inventoried information of the site must be had to know the characteristics; both the pavement and the site where it is. The application of models that help to measure the serviceability of pavements can help us to guarantee the optimal conditions of these, through policies associated with the performance of periodic maintenance without resorting to common practices such as the total replacement of the road infrastructure once may its useful life come to an end. With these policies, safety, mobility, and even the economy of the city can be improved, since it is expected that there will be a considerable reduction in operating costs associated with the quality of the road infrastructure.

\section{State of Art}

Studies of behavior, serviceability, and pathologies in rigid and flexible pavements demonstrate the importance of identifying certain phenomena that contribute to accelerated aging and deterioration of road infrastructure. To carry out an evaluation of the functional or structural situation and thus propose preventive and corrective solutions, some existing methodologies are used, such as the PCI (pavement condition index) methodology. This methodology allows us to make an evaluation of a superficial and very uni structural nature, although within the damages that are evaluated, causes of structural failures are analyzed, providing a measurement of the current conditions of the pavement taking as a reference the failures observed on its surface.

Pavement damage can be due to high traffic loads such as marked variations in temperature. As for the sub grade, if the resistance of the soil at a given point is less than the induced stresses, the failure will occur from the elastic point of view. Now, if the soil element is confined, an additional capacity is generated that prevents the general failure from occurring, a plasticization of the material, creep, and transmission of stresses to the neighboring material simply occurs at that specific site. At this point, the behavior changes and the initial elasticity considerations are no longer correct and pavement failure may occur ${ }^{(5)}$.

The diagnosis of pavement conditions basically comprises an evaluation of the functional state of the pavement and an evaluation of its structural conditions to detect possible pathologies present in its structure ${ }^{(6)}$. The pathological study of rigid and flexible pavements shows the importance of identifying certain phenomena involved in the generation of deterioration of these structures anywhere in the world, to carry out an evaluation of the functional and structural situation and thus propose preventive and corrective solutions to the defects found, consequently, improve mobility for a prolonged period that justifies the investment made. 
In Colombia there is a deficit in terms of programs or entities that regulate all these quality parameters, in recent years road administration tools have been developed so that the authorities have both technical and subjective support for investment in road infrastructure urban ${ }^{(7)}$. Within a study carried out in one of the main cities of Colombia, it was possible to detect that one of the main causes of damage to the rigid pavement is the increase in tides and the phreatic level ${ }^{(8)}$. Within this research it was found that the average condition index of the city under study corresponds to a regular assessment. It was also concluded that the district authorities do not implement any type of preventive maintenance plan for the road system in the city of Cartagena, much less for the road network in the neighborhoods ${ }^{(9)}$.

\section{Materials and Methods}

The PCI methodology consists of a visual evaluation of the condition of the pavement, giving them a rating from 0 to 100 , with 0 being for failed pavement and 100 for excellent. In this method, the degree of severity of the traffic quality is established in such a way that: L (Low-Low); M (Medium-Medium); H (High-High) ${ }^{(10)}$.

On the other hand, the methodology used for the relationship with speeds consists of taking the speeds of 400 vehicles; 20 for each section in which we are going to evaluate and make a relationship of the design speeds they should have and those that these sections really have due to the faults they present. The selection of the evaluated sections was chosen for being one of the most popular locations in the city ( Figure 1).

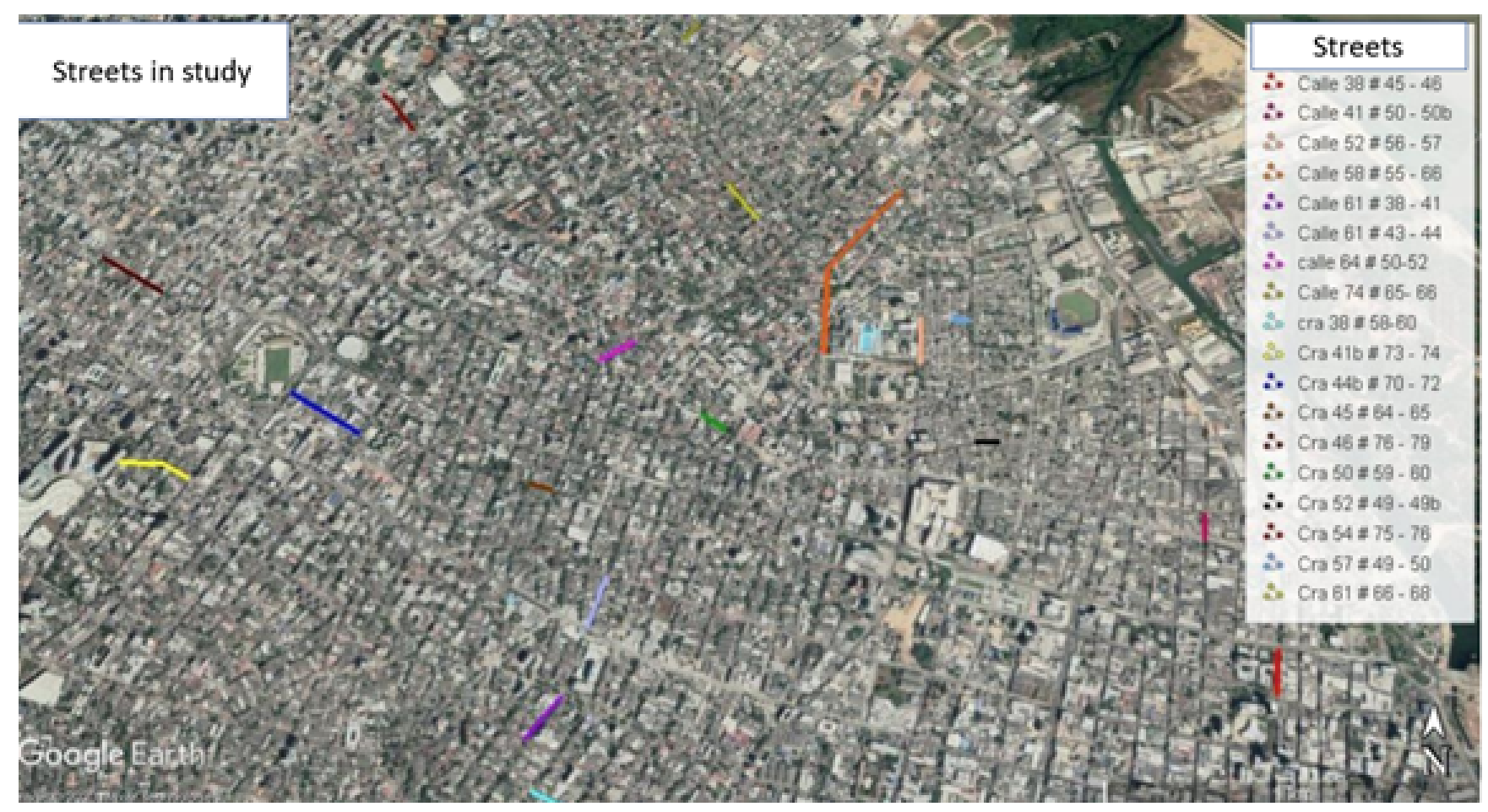

Fig 1. Street in study.

The data collection was carried out as indicated in the specifications of the PCI manual, inventorying the damage per slab and the number of slabs that the section had, the type of damage is also specified and a description of the type of damage is made as shown in the Table 1.

Table 1. PCI damage criteria.

\begin{tabular}{ll}
\hline Number of Damage & Damage \\
\hline 21 & Blow up/buckling \\
22 & Corner fissure \\
23 & Divided slab \\
24 & Durability fissure \\
\hline
\end{tabular}

Continued on next page 


\begin{tabular}{ll}
\hline Table 1 continued & \\
\hline 25 & Scale \\
26 & Joint seal \\
27 & Unevenness \\
28 & Transverse crack \\
29 & Big patch \\
30 & Small patch \\
31 & Polish \\
32 & Pop outs \\
33 & Pumping \\
34 & Punching \\
35 & Railroad crossing \\
36 & Chipping \\
37 & Retraction fissure \\
38 & Corner peeling \\
39 & Joint peeling \\
\hline
\end{tabular}

\section{Results and Discussion}

After collecting data on the damages presented in 20 sections of the city of Barranquilla in the north historic center town and taking the speeds of 20 vehicles in each of the 20 sections, for a total of 400 vehicles speeds; a statistical analysis is carried out.

The first graph shows the most frequent damages and the less frequent damages presented in each section, on the $\mathrm{x}$-axis are the 20 evaluated sections, and on the $y$-axis is the number that represents each damage given in the PCI manual that, as mentioned above, the damages for rigid pavement go from number 21 to 39 ( Figure 2).

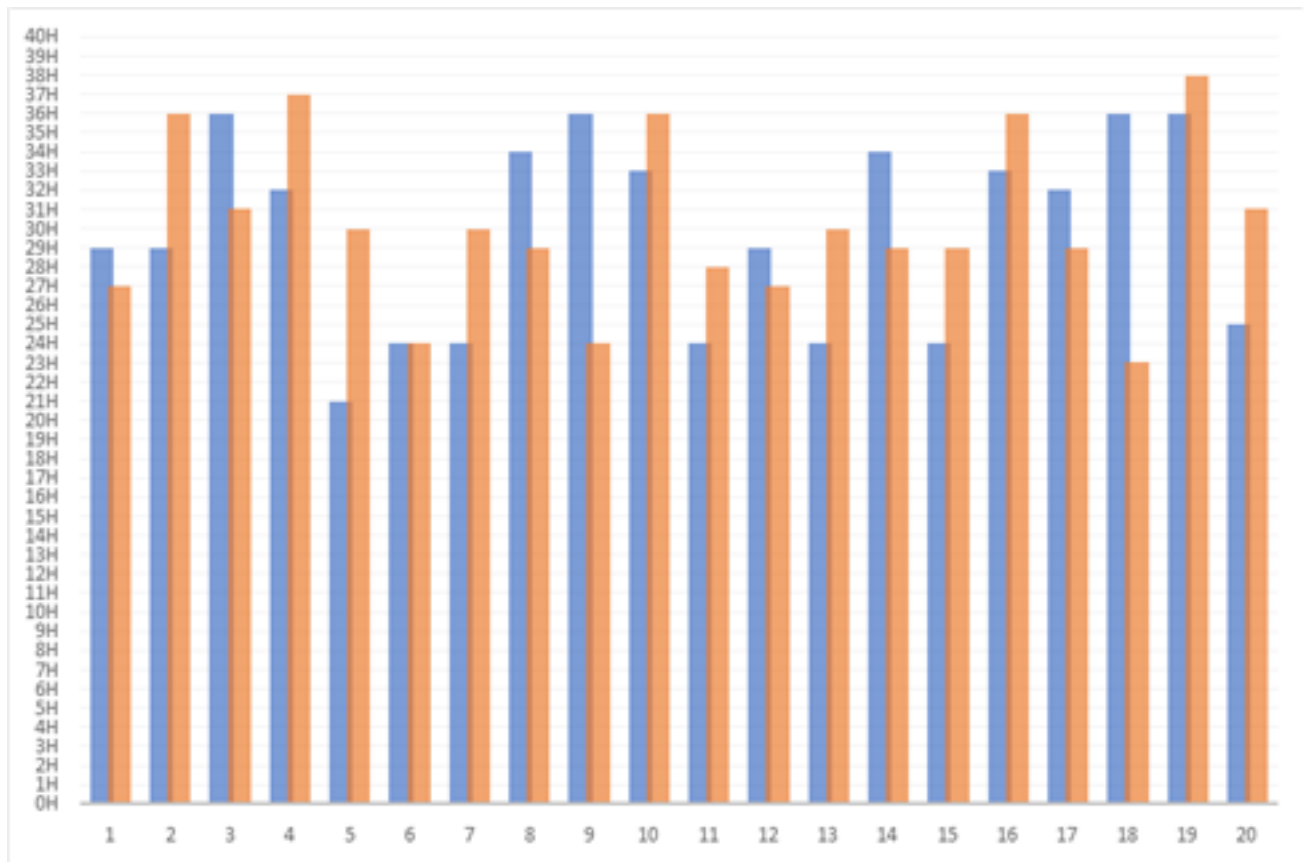

Fig 2. Comparison of level of damages per concrete slab.

In the following graph we can see the number of faults present in all the 20 sections evaluated in the north historic center in the city of Barranquilla in percentages (\%). The most frequent damages present in these sections are patches (of which up to 3 and 4 patches per slab occur), chipping and durability cracks.

On the other hand, graphs of the sections were made individually to be able to visually appreciate the magnitude of the deterioration in which the road is located, as in the following graph which belongs to the first section of Carrera 45 between Calle 76 and 79 , which, according to the software used for the evaluation, saved as a result of a road in poor condition like show in the Figure 3. 


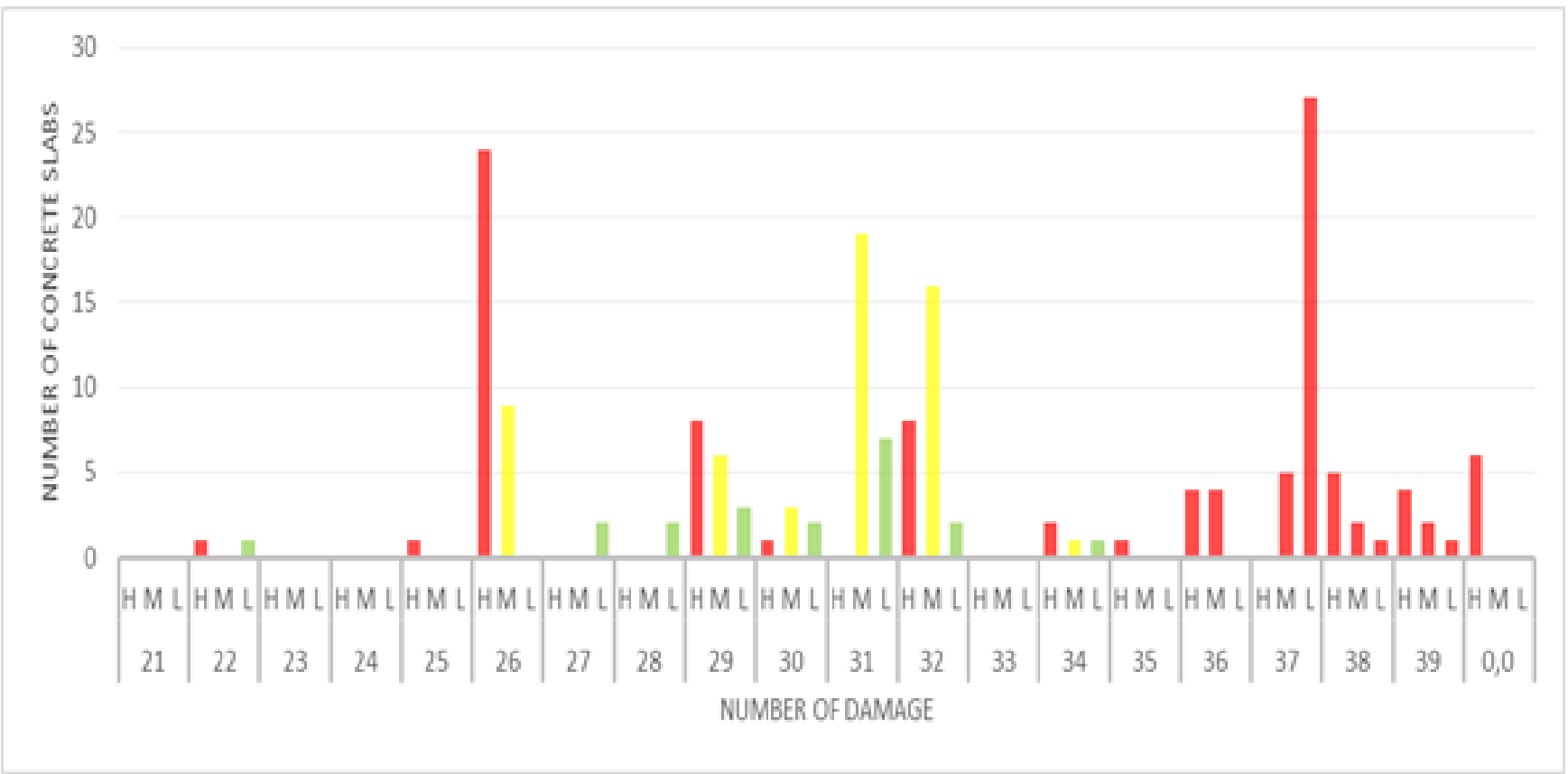

Fig 3. Number of concrete slabs per number of damages.

In the speed graph you can see the duration of the journey of 20 vehicles through one of the evaluated sections, in which two important factors can be highlighted:

1. There are speed ratios $(\mathrm{km} / \mathrm{h})$ lower than those designed, due to the bad conditions in which the road is found, it is not possible to travel smoothly and at the desired speed.

2. There are speed ratios $(\mathrm{km} / \mathrm{h})$ higher than those designed for, due to the conditions of the road, many users of the system instead of reducing speed on a road that is in poor condition, increases it to get through in the shortest time possible.

\section{Conclusion}

In this research, serviceability models of the rigid pavement were evaluated in the north town - historic center of the city of Barranquilla, taking as a reference 20 sections of it: this being a very important and busy area of the city. The method used for this evaluation was the pavement condition index; Also called PCI, this is a visual method which has 19 damage with high $(\mathrm{H})$, medium (M), and low (L) severity.

For the calculation of this same, the UNALPCI software was used, with which the deduced values, densities, the highest damages, and last and foremost the rating of each section were found ${ }^{(10)}$. Thus, concluding that 2 of the 20 sections evaluated are failed, 3 sections in very bad condition, 5 sections in poor condition, 4 sections in fair condition, and 6 sections in good condition; no section was found in excellent condition.

On the other hand, a speed relationship was made in each evaluated section, taking speeds of 20 vehicles per section for a total of 400 vehicles. In this relationship, it could be seen that mobility on these roads is not as expected, on the one hand, the $(\mathrm{km} / \mathrm{h})$ of $15 \%$ of vehicles is lower than expected since the road is in poor condition they cannot go as quickly as expected for security issues. On the other hand, the other $85 \%$ of the vehicles were going at high speeds compared to design, exposing their safety in order not to lag and force the vehicle to go faster than it should be due to the conditions of the tracks. It should be noted that the percentage of vehicles that went faster than the design speed is higher than the lower one because we are in a city in which, unfortunately, there is no good civic culture in a large percentage of the society in which we live ${ }^{(11)}$.

In conclusion, it should be noted that it is vitally important to carry out these evaluations periodically for roads to avoid accidents, guarantee the safety of users, have roads with good breathability, considerably reduce costs to the city by avoiding redoing the roads, and thus to improve the quality of life for all citizens. 


\section{References}

1) Keating P, Fisher JW. Evaluation of fatigue tests and design criteria on welded details. 1986. Available from: http://onlinepubs.trb.org/Onlinepubs/nchrp/ nchrp_rpt_286.pdf.

2) Mora O, Figueroa M, \&amp; Velosa C, Alfonso D. Effect of road quality on fuel consumption and the generation of externalities derived from transport. Case of study: Barranquilla, Colombia. Espacios. 2020;41. Available from: http://www.revistaespacios.com/a20v41n05/a20v41n05p05.pdf.

3) Patterson W. Road Deterioration and Maintenance Effects. Modelo for Planning and Management, Highway Design and Maintenance Standar Model HDM-III. Transportation Department. 1987.

4) Interim Guide for Design of Pavements Structures. 1972. Available from: http://onlinepubs.trb.org/Onlinepubs/nchrp/nchrp_rpt_128.pdf.

5) Badillo J, Rodriguez R. Mecanica de Suelos II. Ciudad de Mexico . 1973. Available from: https://books.google.es/books?id=FK7MgzytR6EC\&printsec= frontcover\&hl=es\# $\mathrm{v}=$ onepage $\& \mathrm{q} \& \mathrm{f}=$ false.

6) Thenoux G, Gaete R, Chile CD. Evaluación técnica del pavimento y comparación de metodos de diseño de capas de refuerzo asfáltico. 1995. Available from: http://www.ricuc.cl/index.php/ric/article/view/364/pdf.

7) Nuñez R. Estudio de los daños del pavimento rigido en algunas calles de los barrios Laguito, CastilloGrande y Bocagrande en zonas con nivel freatico alto en la ciudad de Cartagena. Cartagena. 2015. Available from: https://repositorio.unicartagena.edu.co/bitstream/handle/11227/1546/informe\%20final\% 20de\%20federico\%20\%20RAMOS\%201.2.pdf?sequence=1\&isAllowed $=y$.

8) Barrantes R, Sibaja, Porras D, Jose. Desarrollo de herramientas de gestión con base en la determinación de índices red vial nacional. 2009. Available from: https://revistas.ucr.ac.cr/index.php/ingenieria/article/view/7270/6947.

9) Bonfante, Zarate, Montes. Diagnóstico del estado del pavimento en la red vial del barrio los caracoles en la ciudad de Cartagena. 2015. Available from: http://hdl.handle.net/11227/1547.

10) Vásquez L. Pavement Condition Index (PCI) Para pavimentos asfálticos y de concreto en carreteras. 2002. Available from: https://sjnavarro.files.wordpress. com/2008/08/manual-pcil.pdf.

11) Idu, Desarrollo ID, Urbano. 2009. Available from: https://www.idu.gov.co/web/content/7459/estimacion_costos_usuarios.pdf. 